\title{
Téoros
}

Revue de recherche en tourisme

\section{Le sanctuaire Notre-Dame-du-Cap}

Parmi les lieux de pèlerinage québécois

\section{Marc Lortie}

Volume 16, numéro 2, été 1997

Tourisme et religion

URI : https://id.erudit.org/iderudit/1074584ar

DOI : https://doi.org/10.7202/1074584ar

Aller au sommaire du numéro

Éditeur(s)

Université du Québec à Montréal

ISSN

0712-8657 (imprimé)

1923-2705 (numérique)

Découvrir la revue

\section{Citer ce document}

Lortie, M. (1997). Le sanctuaire Notre-Dame-du-Cap : parmi les lieux de pèlerinage québécois. Téoros, 16(2), 51-52. https://doi.org/10.7202/1074584ar d'utilisation que vous pouvez consulter en ligne.

https://apropos.erudit.org/fr/usagers/politique-dutilisation/ 


\section{f \\ LE SANCTUAIRE Notre-Dame-DU-CAP}

PARMI LES LIEUX DE PÈLERINAGE QUÉBÉCOIS

Marc Lortie, o.m.i., directeur des pèlerinages

Sanctuaire Notre-Dame-du-Cap, Cap-de-la-Madeleine

Depuis les origines du christianisme, la permanence du pèlerinage s'impose. Le pèlerinage, multiforme dans ses manifestations, s'enracine dans le caur des hommes, dans leur appétit du sacré, leur quête d'absolu, leur quête de la trace de Dieu dans le monde.

\section{L'ORIGINE DU PĖLERINAGE}

L'Église ne crée pas le pèlerinage ; elle l'authentifie, l'organise, le discipline. Dans une religion aussi rationnelle que le christianisme, le pèlerinage est la porte ouverte sur le surnaturel, la route entre la terre et le ciel.

\section{UN SANCTUAIRE MARIAL NATIONAL}

Le sanctuaire marial national de NotreDame du Cap au Cap-de-la-Madeleine est un témoin de cette dévotion mariale qui s'est développée depuis 300 ans au Québec par l'ếtablissement d'une Confrérie du Saint-Rosaire en 1694 (une

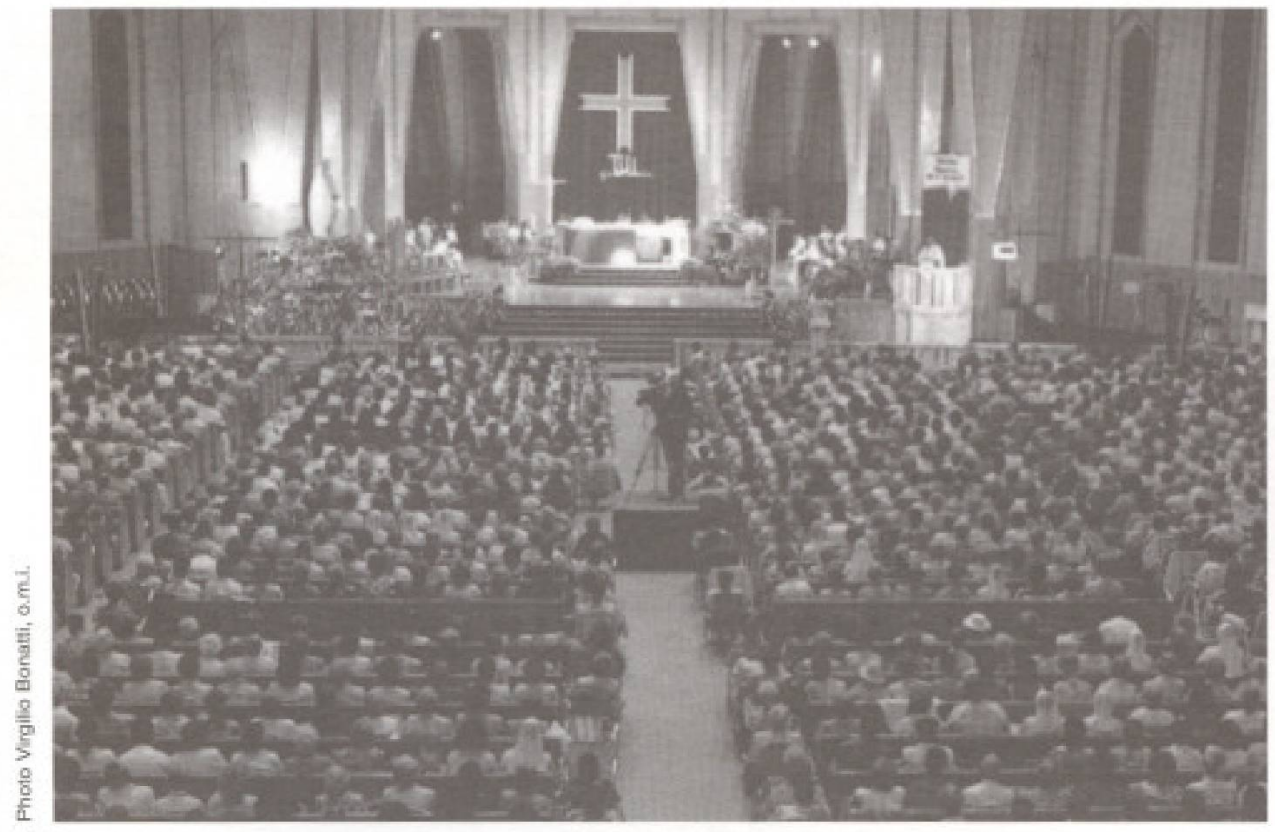

Interieur de la Basilique du Sanctuaire Notre-Dame-du-Cap, Cap-de-la-Madeleine. des premières au Canada), et par l'ouverture en 1720 de la première église paroissiale en pierre (devenue le petit sanctuaire dédié à Marie). C"est la plus ancienne église conservée dans son intégrité au Canada. Le développement de cette dévotion mariale aboutira à la construction (1955-1964) de la basilique dotée de verrières remarquables et uniques en Amérique du Nord, reuvres du maître hollandais, Jan Tillemans, o.m.i.

\section{LES LIEUX DE PÈleRINAGes Au QuÉbec}

Au Québeć, plusieurs lieux de pèlerinages sont les témoins de la foi de nos ancêtres et des différentes dévotions du peuple québécois. Une association regroupe les responsables des principaux sanctuaires du Québec : Basilique de Québec (Québec), Beauvoir (Bromptonville), Ermitage Saint-Antoine (Lac Bouchette), La Réparation (Montréal), Marie-Reine-des-Coutrs (Montréal), Mère d'Youville (Varennes), Montmartre Canadien (Sillery), Notre-Dame-deLourdes (Rigaud), Notre-Dame-desDouleurs (Pointe Navarre, Gaspé), Notre-Dame-du-Cap (Cap-de-la-Madeleine), Oratoire Saint-Joseph (Montréal), Sainte-Anne-de-Beaupré, Sainte-Annede-Pointe-au-Père, Marie-Reine-desCours (Chersey).

\section{LA CLIENTÈLE DES SANCTUAIRES}

La fréquentation de ces sanctuaires est diversifiée. Dans les trois grands sanctuaires au Québec, on évalue comme suit le 
nombre de pèlerins : environ deux millions et demi à l'Oratoire Saint-Joseph ; deux millions à Sainte-Anne-de-Beaupré et 700000 au Sanctuaire Notre-Damedu-Cap. La saison des pèlerinages commence au début de mai pour se terminer à la mi-octobre, sauf à l'Oratoire SaintJoseph, en plein centre de Montréal, qui est ouvert toute l'année.

\section{LES MOTIVATIONS SONT TRÈS VARIÉES}

La motivation des gens qui viennent dans ces hauts lieux de prières et de célébrations est très variée. Nous avons l'habitude de discemer assez allègrement entre le pèlerin (celui qui fait une démarche de foi et revient transformé) et le touriste religieux (celui qui visite, fait la découverte d'un nouveau lieu, admire la beauté des édifices et contemple la beauté des lieux sacrés). La réalité dépasse largement cette distinction. Les sanctuaires attirent une variété de personnes : groupes de pèlerins qui viennent chaque année prier et célébrer, faire une expérience de foi ; celui qui vient trouver une oasis de paix et de calme; celui qui ne pratique pas régulièrement, mais qui veut être accueilli et éclairé dans sa quête de spiritualité ; celui qui, influencé par les théories du Nouvel Âge, y trouve l'énergie souhaitée; le couple qui confie à Marie son projet de vie et demande la bénédiction du Seigneur ; les pèlerins qui viennent à pied faire leur pèlerinage et confier leurs intentions de priêres à Dieu (l'an passé, à Notre-Dame-du-Cap, 1000 personnes sont venues de Québec, de Montréal, de Sherbrooke, etc., marchant près de 180 kilomètres en neuf jours) ; celui qui admire la beauté des vitraux ou écoute les orgues; celui qui savoure le calme des jardins ou allume un lampion, symbole de sa prière à Dieu. L'un achète un objet de piété et le fait bénir pour obtenir la protection d'en-haut ; l'autre vient chercher la force. Une grandmaman vient confier à Marie enfants et petits-enfants ; une autre vient vivre la neuvaine de l'Assomption, etc.

\section{LA RELIGIOSITÉ POPULAIRE}

Les sanctuaires favorisent l'expression de la religiosité populaire, religion du geste et de l'émotion plutôt que le rationnel. Cette expression du sacré doit être judi-

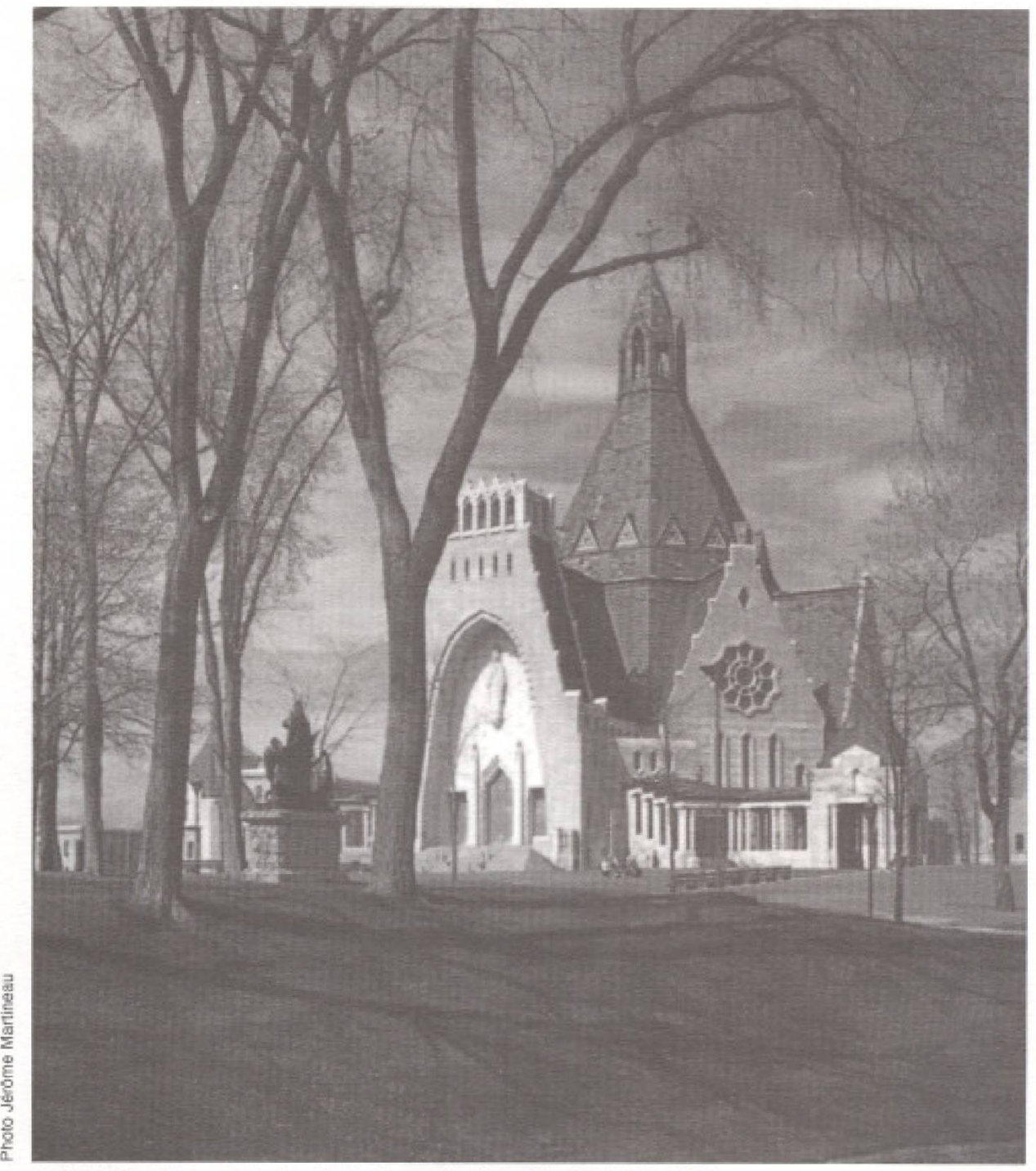

La Basilique du sanctuaire Notre-Dame-du-Cap, Cap-de-la-Madeleine.

cieusement accueillie et éclairée pour que l'âme d'un peuple s'exprime. Pensons aux amérindiens, surtout aux Montagnais, qui aiment visiter les sanctuaires pour honorer la grand-maman sainte Anne, spécialement le 26 juillet, jour de sa fête (à Sainte-Anne-de-Beaupré, à la chapelle de la Montagne Bleue près de Natashquan ou à la chapelle sur l'île en face de la Romaine sur la Basse CôteNord). Plusieurs groupes ethniques aiment se regrouper dans les sanctuaires pour exprimer leur foi dans leur langue et selon leurs coutumes.

Les sanctuaires du Québec sont dans la lignée des grands sanctuaires de l'Europe : Lourdes en France, Sainte-Anne d'Auray en Bretagne et Sacré-Cour de Montmartre à Paris.

\section{BIBLIOGRAPHIE}

(1992), Conseil Pontifical pour la Pastorale des Migrants et Itinérants, Actes du $I^{\text {" }}$ Congrès Mondial de Pastorale des Sanctuatres et des Pelerinages, Rome 26-29 février, Cité du Vatican.

Chélini, Jean, et Henry Branthomme (1982), Les Chemins de Dieu : Histoire des pèlerinages chrétiens des origines à nos jours, Paris, Hachette.

Charron, André (1995), * L'Oratoire SaintJoseph, espace et fonction de l'Église de la ville : un sanctuaire dans la mission urbaine $*$, Faculté de théologie, Université de Montréal. 